\title{
The DSC Model for the Nonlinear Analysis of In-plane Loaded Masonry Structures
}

\author{
A.H. Akhaveissy* \\ Department of Civil Engineering, Faculty Engineering, Razi University, P.O. Box: 67149-67346, Kermanshah, Iran
}

\begin{abstract}
A nonlinear finite element method with eight-noded isoparametric quadrilateral elements is used to predict the behavior of unreinforced masonry structures. The disturbed state concept (DSC) with modified hierarchical single yield surface (HISS) plasticity which is called DSC/HISS-CT is used to characterize the constitutive behavior of masonry in both compression and tension. The model uses two HISS yield surfaces for compressive and tensile behavior. The DSC model allows for the characterization of non-associative behavior through the use of disturbance. It computes microcracking during deformation, which eventually leads to fracture and failure. the critical disturbance, $\mathrm{D}_{\mathrm{c}}$, identifies fracture and failure. In the DSC model the DSC model was validated at two levels: (1) specimen and (2) practical boundary value problem. At the specimen level, predictions are obtained by integrating the incremental constitutive relations. The proposed constitutive model is verified by comparing numerical predictions with results obtained from test data; the comparisons are found to be highly satisfactory. A new explicit formula is also presented to estimate the strength of unreinforced masonry structures.
\end{abstract}

Keywords: Masonry wall, disturbed state concept, softening behavior, macro modeling, compressive behavior, tensile behavior.

\section{INTRODUCTION}

Masonry buildings are constructed in many parts of the world where earthquakes occur. Hence, knowledge of their seismic behavior is necessary to evaluate the seismic performance of these types of buildings. Pushover analysis is commonly used to evaluate seismic performance and determine the capacity curve. Therefore, the capacity curve of unreinforced masonry buildings studied in this paper.

An approach for analysis of unreinforced masonry buildings is the macro-modeling of masonry as a composite material. The macro modeling is more practice oriented due to the reduced time and memory requirements as well as a userfriendly mesh generation. The compressive strength of a masonry unit is an important parameter in the analysis of unreinforced masonry buildings using the macro-element method. A masonry unit includes mortar joints and masonry bricks. The compressive strength for masonry units with different mortar was evaluated in previous researches [1-5].

SAP2000 v.10, a software package with a user-friendly interface which is widely used by practicing engineers, was used for the seismic analyses of masonry buildings [6]. Two unreinforced stone masonry walls in the Catania Project were modeled with SAP2000 v.10. The static pushover curves from the analyses were compared with predicted

*Address correspondence to this author at the Department of Civil Engineering, Faculty Engineering, Razi University, P.O. Box: 6714967346, Kermanshah, Iran; Tel.: +98 831427 4535; Fax: +98 831427 4542; E-mail: Ahakhaveissy@razi.ac.ir results from the SAM code, which was developed by the University of Pavia, the Genoa research group and the Basilicata research group [6]. The Basilicata research group used a no-tensile-strength macro-element model with crushing and shear failures while the Genoa research group used a finite element model with layer failures. The ultimate base shear force for wall A was predicted to be $1682 \mathrm{kN}$ by the Genoa R.G., $1339 \mathrm{kN}$ by SAP2000, $1115 \mathrm{kN}$ by the SAM code, and $1395 \mathrm{kN}$ by the Basilicata R.G. Accordingly, the ultimate base shear force for wall B is predicted to be 650 $\mathrm{kN}$ by the Genoa R.G., $474 \mathrm{kN}$ by the SAM code and SAP 2000, and $508 \mathrm{kN}$ by the Basilicata research group. These results show differences between the different studies. Hence, they may lead to the confusion of practicing engineers, because they can not figure out which codes or research results are the most applicable or precise.

The in-plane shear behavior of hollow brick masonry panels was evaluated [7]. The nonlinear behavior of masonry was modeled assuming elastic-perfectly plastic behavior, Drucker-Prager, of the mortar joint in the ANSYS 5.4 commercial software. In other words, the micro-element method was used to analyze the panels. A comparison between the experimental results and numerical analysis shows good agreement. A macro-element approach to the threedimensional seismic analysis of masonry buildings was applied [8]. The full model displays a base shear force which is approximately $25 \%$ higher than the value calculated for the plane structure. Seismic fragility of an unreinforced masonry low-rise building was studied using a structural modeling method. The method utilizes a simple, composite nonlinear 
spring. In this method, the wall is divided into distinct areas or segments. Each segment of the unreinforced masonry wall is then represented by a nonlinear spring, and the springs are assembled in series and in parallel to match the segment topology of the wall [9]. Rota et al. [10] presented a new analytical approach for the derivation of fragility curves for masonry buildings. The methodology was based on nonlinear stochastic analyses of building prototypes. Monte Carlo simulations were used to generate input variables from the probability density functions of mechanical parameters.

The seismic performance of existing unreinforced masonry buildings in North America was considered in a stateof-the-art paper [11]. The various failure modes of unreinforced masonry buildings subjected to earthquake excitation were described in the paper. The damage to the existing buildings for different earthquake scenarios was evaluated.

The static pushover curve was studied using the boundary element method for unreinforced masonry walls [12]. In the analysis, a no-tension-material with an infinite strength in compression was adopted to model the masonry buildings. The predicted results showed good agreement with experimental data.

Milani et al. [13] performed a three-dimensional homogenized limit analysis to determine the ultimate lateral load of full masonry structures. Linearized homogenized surfaces for masonry in six dimensions $[14,15]$ were obtained and implemented in a finite element code. Comparisons between the predicted results from the 3D homogenized limit analysis and experimental data show an error of approximately $12 \%$. Milani et al. [16] also used a 3D homogenized limit analysis for full masonry buildings reinforced by FRP. The error between the predicted results and experimental data for a two-story masonry building is $4.6 \%$ in the absence of FRP and $9.4 \%$ in the presence of FRP. Milani [17, 18] applied the 3D homogenized limit analysis to determine the limit load of a wall under in-plane and out-plane loading.

A simple equilibrium model was used to estimate the ultimate capacity of masonry shear walls. The model was based on strut-and-tie schemes representing the combination of the compression or tension stress fields at the ultimate condition. Comparisons between the performance of the model and experimental results for dry-joint and mortar-joint masonry show good agreement. [19]

A finite element analysis conducted for a single-story, one-room masonry building, with different aspect ratios and with different positions of wall openings, subjected to a seismic force with varying direction [20]. The response spectrum method was employed for the analysis. The predicted results show that the critical direction of seismic force for the development of maximum stresses in the walls of a room occurs when the opening is along the short wall of the room. It was also observed that the maximum principle tensile stress occurred in the short wall, and the maximum shear stress occurred in the long wall.

The analysis of unreinforced masonry buildings employed a two-step approach [21]. In step 1, the ultimate bending moment - shear force strength domains of the masonry spandrels were derived by means of a heterogeneous upper-bound finite element limit analysis. The results were stored in a database. In step 2, an equivalent frame model of the masonry wall was assembled. In the frame model, the spandrels were modeled as elastic Timoshenko beams. At each analysis step, a check was performed to determine whether the internal forces of these coupling beams were smaller than the failure loads stored in the database created in step 1 . The shear force and bending moment capacity of the piers were simply estimated according to the Italian Design code. The proposed analysis approach was appeared capable of deriving the pushover curve of unreinforced masonry walls [21]. A constitutive model was developed on the basis of homogenized anisotropic elasto-plasticity for analysis of unreinforced masonry. The effect of anisotropy was introduced by a fictitious isotropic stress and strain space. The advantage of this model is that the classical theory of plasticity can be used to model nonlinear behavior in the isotropic spaces [22].

A rigid-body numerical model was used to identify the minimum height-to-thickness ratio that would cause the wall to collapse when subjected to different out-of-plane ground motions [23]. The spectral accelerations of the ground motions were selected to be $0.24 \mathrm{~g}, 0.3 \mathrm{~g}, 0.37 \mathrm{~g}$ and $0.44 \mathrm{~g}$. The model was calibrated using the results of full-scale shake table tests of a wall with a height to thickness ratio of 12 [24]. The results of the analysis showed that when a wall is subjected to a spectral acceleration of $0.44 \mathrm{~g}$. The probability of collapse for height-to-thickness ratios less than 10 is less than $1 \%$. The ratios for spectral accelerations of $0.24 \mathrm{~g}$ and $0.3 \mathrm{~g}$ are 18 and 15, respectively [23]. Therefore, walls with the conditions described above will be stabilized when subjected to out-of-plane ground motions. More over the inplane strength of the wall will be important in resisting lateral forces.

Akhaveissy [25] presented a new close form solution to determine the shear strength of unreinforced masonry walls. Predicted results show less error percentage than ATC and FEMA-307 [26]. The new explicit formula is based on results of proposed interface model by Akhaveissy [25]. Consequently, the proposed closed form solution can be used satisfactorily to analyze unreinforced masonry structures.

The research results related to macro-modeling processes which discussed above show considerable differences between various methods of macro-modeling in comparison with test data [6].

The research described above on the numerical analysis of masonry walls shows that numerous researchers have modeled the behavior of masonry walls using the micromodeling approach which is suited for the analysis of small masonry walls. However, the macro-modeling approach can be used for the analysis of large practical problems. Therefore, investigations into the use of macro-modeling, based on an appropriate constitutive law for the analysis of masonry walls, are recommended and are the focus of this paper. In this paper, the disturbed state concept and hierarchical single surface (DSC/HISS) model is modified to analyze masonry 
structures in which different HISS single surfaces are used for the compressive and tensile behaviors of the masonry. The modified model is called DSC/HISS-CT, where CT denotes compression and tension. The base model (HISS) was introduced by [27-31]; a brief description is given below.

The DSC/HISS model is a unified and hierarchical model which can be used to characterize elastic, plastic and creep deformations, as well as micro-cracking that leads to fracturing and failureing, degradating or softening, and healing or strengthening. It has been used to model a wide range of materials such as clays, sands, concrete, asphalt concrete, ceramic, metals, alloys and silicon, as well as interfaces and joints [31]. It has been implemented in nonlinear finite element procedures to solve a wide range of engineering problems including two- and three-dimensional [31-33] and cyclic loading [31, 34, 35] problems. Thus, the DSC model has a number of advantages compared with other available models that often account for only specific behavioral aspect(s). The DSC/HISS models have also been used to model the behavior of concrete and rocks [28, 30, 31]. In this paper, the DSC model is used for unreinforced masonry structures. The new feature is the use of the HISS yield function for yield in both compression and tension.

\section{DISTURBED STATE CONCEPT WITH HISS MODEL}

The following description of the DSC model is adopted from various publications, e.g., [27-31]. In this model, a deforming material element is assumed to be composed of two (or more) reference states, the relatively intact (RI) and the fully adjusted (FA) Fig (1). The material is assumed to be transformed continuously from the relative intact (RI) state to the fully adjusted (FA) state, Fig (1a), at randomly distributed locations under external excitations such as mechanical and thermal loading. The transformation involves micro-structural changes that cause particle reorientation and relative motions. The observed behavior is expressed in terms of the RI and FA states using the disturbance function, $\mathrm{D}$, which acts as a coupling or interaction mechanism between the RI and FA states, Fig (1b). The disturbance grows as the material deforms and the plastic strain (or work) accumulates. Thus, DSC intrinsically includes coupling in which the micro-cracked (damaged) or fully adjusted part also contributes to the response of the material. The RI and FA states can be defined using various models. Continuum elasticity or plasticity can be used to model the response of the RI state while the FA state can be assumed to carry only

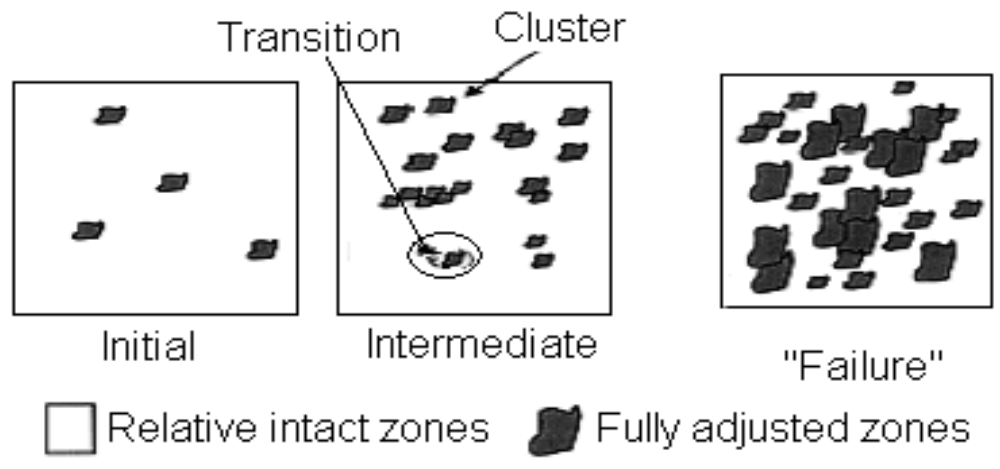

(a)

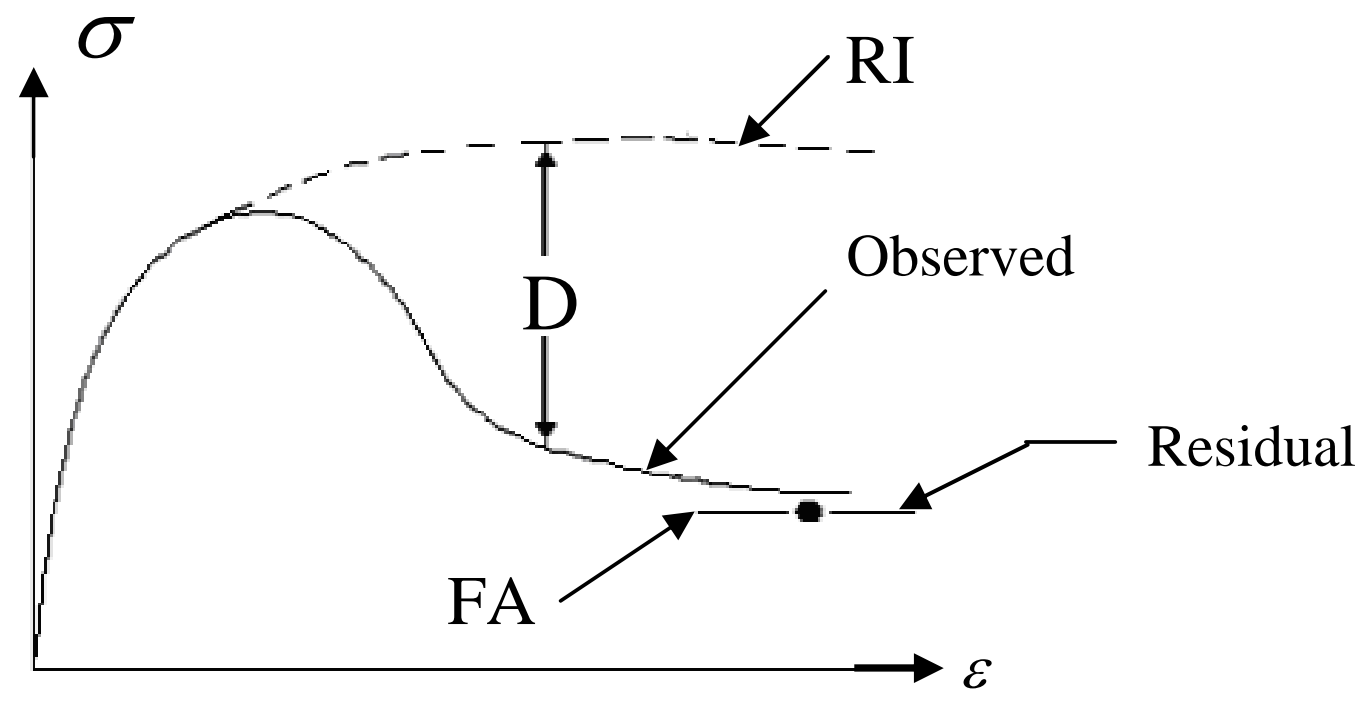

(b)

Fig. (1). (a) RI and FA states in DSC, and (b) disturbance as a coupling between the RI and FA states. 


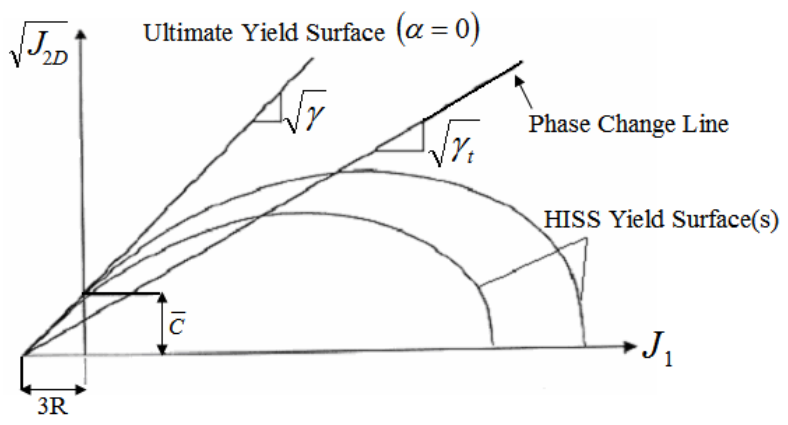

Fig. (2). HISS yield surface in $J_{1}-\sqrt{J_{2 D}}$ space.

hydrostatic stress or can be modeled using the critical state model [31]. Brief description of the models for the RI and FA states and the disturbance used in the DSC model are given below.

\subsection{Relative Intact (RI) State}

The hierarchical single-surface (HISS) plasticity model [27] provides a general formulation for the elasto-plastic characterization of material behavior. It involves a single continuous yield surface compared with some previous models which involved multiple (discontinuous) yield surfaces that resulted in computational difficulties. This model which allows for isotropic and anisotropic hardening as well as associated and non-associated plasticity characterizations can be used to represent material responses based on the continuum plasticity theory $[27,31]$. In the HISS model, the RI state is usually defined by the associated plasticity; accordingly, the yield function, F, Fig. (2), is given by

$F=\bar{J}_{2 D}-\left(-\alpha \bar{J}_{1}^{n}+\gamma \bar{J}_{1}^{2}\right)\left(1-\beta S_{r}\right)^{-0.5}=0$

$\bar{J}_{2 D}=J_{2 D} / p_{a}{ }^{2}$

$\bar{J}_{1}=\left(J_{1}+3 R\right) / p_{a}$

$S_{r}=\frac{\sqrt{27}}{2} \cdot \frac{J_{3 D}}{J_{2 D}}$

where $J_{2 D}$ and $J_{3 D}$ are the second and third invariants of the deviatoric stress tensor, respectively. $J_{1}$ is the first invariant of the total stress tensor, $p_{a}$ is the atmospheric pressure, $\mathrm{R}$ is the reference stress and is used mainly to include the intercept $(\bar{c})$ Which is proportional to the cohesive strength Fig. (2). $\gamma$ and $\beta$ are related to the ultimate condition. The hardening or growth function for the plastic yield can be expressed as

$\alpha=\frac{a_{1}}{\xi^{\eta_{1}}}$

where $a_{1}$ and $\eta_{1}$ are the hardening parameters, and $\xi$ is the trajectory or the accumulated plastic strains. Using F, Eq. (1a), the incremental stress-strain equations for the RI (plasticity) model are derived as [31]:

$$
\begin{aligned}
& d \sigma=\left[C^{e}-\frac{C^{e}\left(\frac{\partial Q}{\partial \sigma}\right)\left(\frac{\partial F}{\partial \sigma}\right)^{T} C^{e}}{\left(\frac{\partial F}{\partial \sigma}\right)^{T} C^{e}\left(\frac{\partial Q}{\partial \sigma}\right)-\frac{\partial F}{\partial \xi} \gamma_{F}}\right] d \varepsilon \\
& \gamma_{F}=\left[\left(\frac{\partial Q}{\partial \sigma}\right)^{T}\left(\frac{\partial Q}{\partial \sigma}\right)\right]^{1 / 2}
\end{aligned}
$$

where $\sigma$ is the stress vector, $C^{e}$ is the elastic constitutive matrix, d denotes an increment, and $Q$ is the plastic potential function. When the associated flow rule is adopted, $F \equiv Q$.

The compressive stress is assumed to be positive for geologic materials and masonry. The yield surface, $F$ is valid for compressive behavior in the positive $J_{1}-\sqrt{J_{2 D}}$ space, Fig. (2). The behaviors of materials such as concrete and masonry are different under compression and tension; thus, the yield surface, Fig. (2), is not appropriate on the negative $J_{1}$-axis. A ad hoc model such as the stress transfer approach [36], is often used. In this approach, the computed tensile stress above the tensile strength is redistributed in the zone of the problem. The HISS model can be used for both compression and tension if the material parameters are determined from appropriate laboratory tests under compression and tension. A model, called DSC/HISS-CT can account for both compression and tension yield. The model was introduced in [33, 37, 38]. However, DSC/HISS-CT has not yet been used for the unreinforced masonry practice buildings presented in this paper. Fig. (3) shows yield surfaces for compression and tension. As it can be seen, although the yield surfaces plotted in the same stress space for convenience, are different from each other. Besides, their parameters are determined from relevant compression or tension tests. The yield surfaces in tension and compression are expressed in stress space in terms of $J_{1}, J_{2 D}$ and $J_{3 D}$, which include all components of the stress vector in threedimensional space. A hierarchical single yield surface has also been implemented in nonlinear finite element proce-

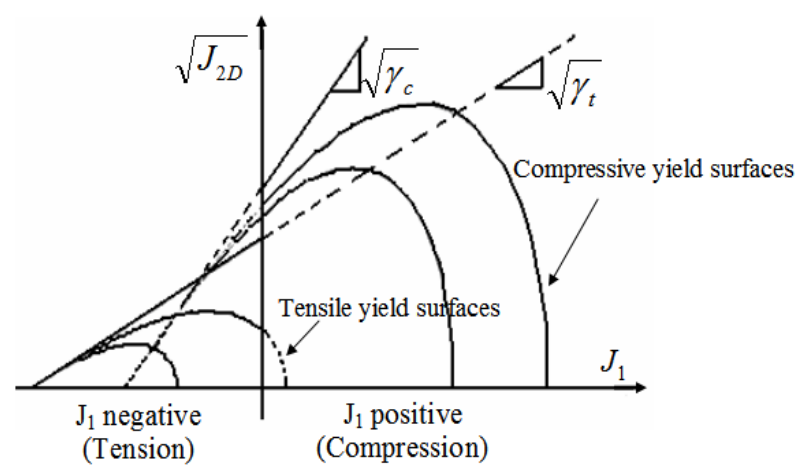

Fig. (3). Schematic of compressive and tensile HISS yield surfaces in $\mathrm{J}_{1}-\sqrt{J_{2 D}}$ Stress Space [37]. 
dures to solve a wide range of two- and three-dimensional engineering problems [31-33]. Therefore, the model can be used to analyze unreinforced masonry structures as 3D boundary value problems and can include the out-of-plane seismic effects.

\subsection{Fully Adjusted (FA) State}

Various characterizations of the behavior of the FA state are given in Desai [31]. In a simple form, the FA state for masonry can be considered using residual stress in the stressstrain curve response, Fig. (1b). Fully adjusted stress can also be based on approximately $20 \%$ of the compressive resistance of masonry in uniaxial tests [2], and the residual stress has been considered as $14 \%$ of the compressive resistance of masonry in uniaxial tests [39].

\section{Disturbance}

Disturbance, $D$, can be defined in terms of measured stress, void ratio, pore water pressure, and nondestructive properties, such as P or S wave velocities [31]. In terms of stress, it is defined as:

$D=\frac{\sigma_{i}-\sigma_{a}}{\sigma_{i}-\sigma_{c}}$

where $\sigma_{i}, \sigma_{a}$ and $\sigma_{c}$ are RI, observed and FA stress values, respectively. To introduce D in the DSC model, Eq. (6), it needs to be expressed in a mathematical form in terms of basic variables, such as accumulated plastic strains or work. Hence, D is expressed in terms of the accumulated deviatoric plastic strains using the Weibull [40] type function:

$$
D=D_{u}\left[1-\exp \left(-A \xi_{D}^{Z}\right)\right]
$$

where $D_{u}$ is the ultimate disturbance (often assumed to be unity), $\xi_{D}$ is the trajectory of (deviatoric) plastic strains, and $A$ and $Z$ are disturbance parameters. The parameters in Eq. (5) are determined on the basis of the values of the measured $\sigma_{a}$ at various points on the stress-strain curve, Eq. (4), and the corresponding values of $\xi_{D}$.

Akhaveissy and Desai introduced a critical disturbance to show the failure zones $[37,38]$. The value of the critical disturbance, $D_{c}$, was assumed to occur at about 0.9 . The critical disturbance showed that micro-cracking may start when the disturbance is about 0.003 for compression and about 0.0001 for tension. Micro-cracks then grow and coalesce into cracks that lead to fracture or failure at the critical disturbance, $D_{c}=$ $0.9[37,38]$. Thus, $\mathrm{D}$ can be used as a measure to identify the initiation and growth of micro-cracks (based on test data) that lead to fracture and failure. For example, when the disturbance reaches 0.9 or higher values, fractures occur and grow. In finite element analysis, elements that reach this critical value are identified after each load increment; thus, the initiation and growth of fractures are provided progressively by the computer procedure. In later applications, the contours of $\mathrm{D}$ are plotted based on the computational results, and the cracking and fracture are related to the values and extent of the disturbance.

Both the RI and FA states contribute to the material response through disturbance (D) as the coupling function. The following DSC equations in incremental form show this coupling [31]:

$$
d \sigma_{i j}^{a}=(1-D) d \sigma_{i j}^{i}+D d \sigma_{i j}^{c}+d D\left(\sigma_{i j}^{c}-\sigma_{i j}^{i}\right)
$$

where $\mathrm{d}$ denotes an infinitesimal increment, and $\sigma_{i j}$ is the stress tensor. The DSC model in this study is based on small strains. It can be modified by including large strains.

\subsection{Numerical Simulation of Masonry Prism Behavior Laboratory Tests (Fig. 5)}

On

the basis of a number of tests on masonry the following mathematical equations have been used by Kaushik et al. [1, 2] and Pandey and Meguro [39]:

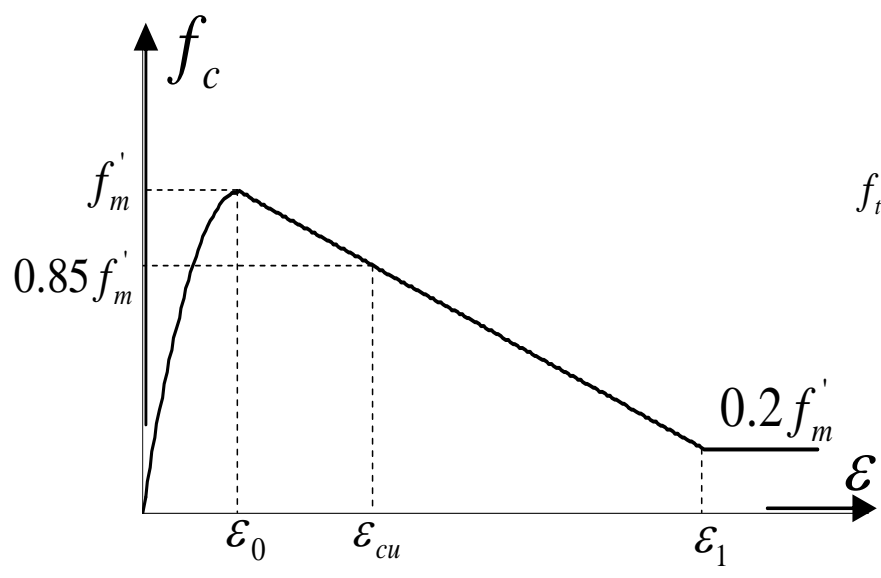

(a)

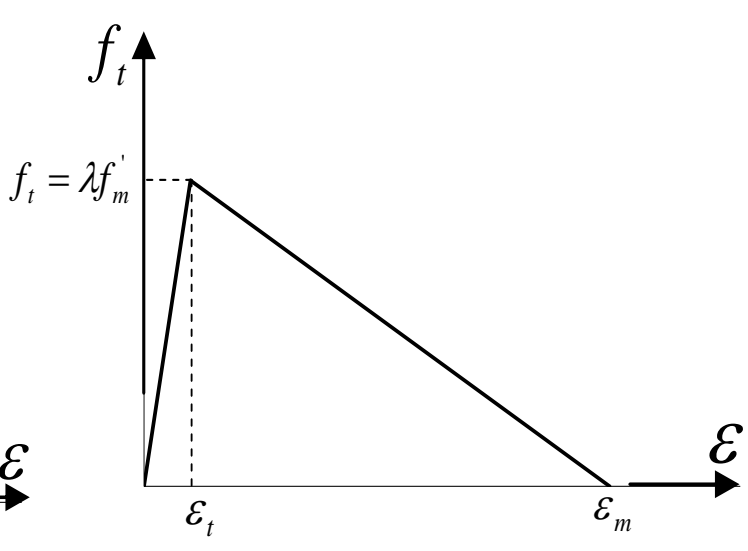

(b)

Fig. (4). (a) Compressive and (b) tensile behavior of a masonry prism. 


\section{For Compressive Behavior:}

$$
\begin{array}{ll}
f_{m}=f_{m}^{\prime}\left[2\left(\frac{\varepsilon}{\varepsilon_{0}}\right)-\left(\frac{\varepsilon}{\varepsilon_{0}}\right)^{2}\right] & \varepsilon \leq \varepsilon_{0} \\
f_{m}=f_{m}^{\prime}\left(1-0.15\left(\frac{\varepsilon-\varepsilon_{0}}{\varepsilon_{c u}-\varepsilon_{0}}\right)\right) & \varepsilon_{0}<\varepsilon \leq \varepsilon_{1} \\
f_{m}=0.2 f_{m}^{\prime} & \varepsilon>\varepsilon_{1}
\end{array}
$$

Eq. 7(a) is Hognestad's model for concrete's compressive behavior [41]. Eq. 7(b) is a linear function between peak stress and residual stress. Eq. 7(c) is the residual stress that is assumed to be $20 \%$ of the peak stress.

\section{For Tensile Behavior:}

$$
\begin{array}{ll}
f_{t}=E_{c} \varepsilon & \varepsilon \leq \varepsilon_{t} \\
f_{t}=\lambda f_{m}^{\prime}\left(1-\frac{\varepsilon-\varepsilon_{t}}{\varepsilon_{m}-\varepsilon_{t}}\right) & \varepsilon>\varepsilon_{t}
\end{array}
$$

Eq. 7(d) is obtained from the elastic behavior of masonry in the tensile region up to the peak tensile stress. Softening behavior occurs after this point. This behavior is modeled by a linear function. Here, a linear function (Eq. 7(e)) is as- sumed to determine the parameters of DSC for the softening behavior of masonry in tension. However, the DSC/HISSCT model accounts for the nonlinear behavior of masonry in the tensile region in terms of an exponential strain function (Eq. 5 and Fig 11). In Eq. 7, $f_{m}^{\prime}$ is the compressive strength of a masonry prism, $0.002 \leq \varepsilon_{0} \leq 0.004,0.003 \leq \varepsilon_{\text {cu }} \leq 0.007[1-2], \quad \varepsilon_{m}=10 \varepsilon_{t}$, $\lambda$ varies between 0.1 to $0.25, E_{c}$ is the modulus of elasticity of masonry, and $\varepsilon_{1}, \varepsilon_{t}$ are shown in Fig. (4). Fig. (4a) shows schematic plots of Eqs. 7(a) to 7(c) for compression, and Fig. 4(b) shows the plot for tension.

Eqs. 7(a) to 7(c) are applied to construct the compressive behavior of masonry prisms. Similarly Eqs. 7(d) and 7(e) are applied to construct for the tensile behavior. In this sense, the stress-strain behavior used here is called "constructed" behavior.

\subsection{Determination of Parameters.}

\begin{tabular}{|c|c|c|c|c|c|c|c|c|c|c|c|c|}
\hline \multirow{2}{*}{ 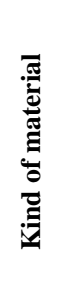 } & \multirow{2}{*}{ 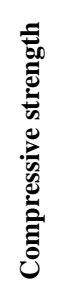 } & \multirow{2}{*}{ 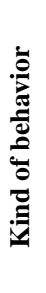 } & \multicolumn{8}{|c|}{ HISS plasticity parameters } & \multicolumn{2}{|c|}{$\begin{array}{c}\text { DSC Parameters (Distur- } \\
\text { bance) }\end{array}$} \\
\hline & & & E & $v$ & $\gamma$ & $\beta$ & $\mathrm{n}$ & $\mathrm{R}$ & $a_{1}$ & $\eta_{1}$ & A & Z \\
\hline \multirow{2}{*}{ 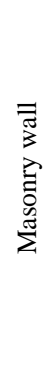 } & \multirow{2}{*}{ 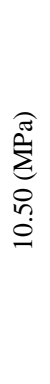 } & 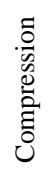 & 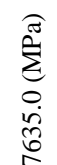 & $\stackrel{2}{\circ}$ & 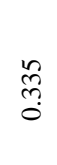 & ঙ্ণি & तु & ষ্ণ & 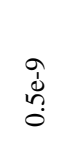 & $\begin{array}{l}\underset{f}{\text { f }} \\
\stackrel{m}{0}\end{array}$ & 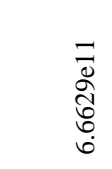 & 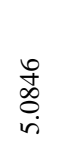 \\
\hline & & 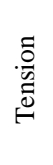 & 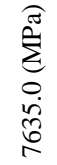 & $\stackrel{10}{?}$ & 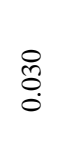 & $\stackrel{?}{\circ}$ & $\stackrel{\stackrel{L}{\rightarrow}}{\rightarrow}$ & \& & 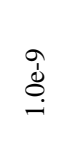 & 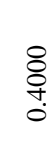 & 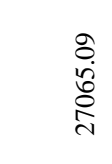 & $\underset{\substack{\text { } \\
\text { m. }}}{ }$ \\
\hline \multirow{2}{*}{ 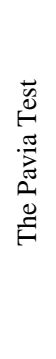 } & \multirow{2}{*}{ 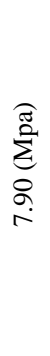 } & 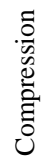 & 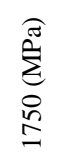 & กี & 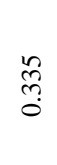 & ?ִ & 䓟 & $\stackrel{R}{i}$ & 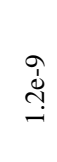 & $\begin{array}{l}\text { षे } \\
\text { ํ. }\end{array}$ & $\begin{array}{l}\mathscr{0} \\
\& \\
\dot{0} \\
0 \\
\&\end{array}$ & 蜼 \\
\hline & & 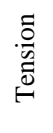 & 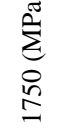 & ָั & 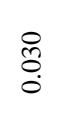 & $\stackrel{\bullet}{0}$ & $\stackrel{\text { L? }}{\circ}$ & ֶָ. & $\stackrel{0}{i}$ & $\stackrel{\nabla}{0}$ & 递 & $\stackrel{8}{\overbrace{}}$ \\
\hline
\end{tabular}

The DSC/HISS-CT parameters are determined based on Eqs. 7(a) to 7(c) for the compressive behavior of masonry prisms and Eqs. 7(d) and 7(e) for the tensile behavior. The

Table 1. Parameters for the DSC/HISS-CT Model 
details on how to determine the parameters are given by Desai [31], Akhaveissy and Desai [37, 38] and Akhaveissy et al. [42]. Table 1 shows the parameters of the model for the compressive behavior of masonry prisms with compressive strengths $f_{m}^{\prime}=10.5$ and 7.9 MPa, respectively. These values for $f_{m}^{\prime}$ are chosen to be consistent with masonry prisms in later applications. Akhaveissy and Desai [37] determined the parameters of the model for the masonry prism with compressive strength $f_{m}^{\prime}=10.5 \mathrm{MPa}$.

\subsection{Specimen Level Validations}

The model is validated at the element level by using the parameters in Table 1 and Eqs. (6) and (3a). At the specimen level, predictions are obtained by integrating the incremental constitutive relations, Eq. (3a). Akhaveissy and Desai [37] compare predicted results of the stress-strain curve from the model for the masonry prism with compressive strengths $f_{m}^{\prime}$ $=10.5 \mathrm{MPa}$ and the constructed stress-strain curves by Eq. 7 . Hence, the stress-strain curve obtained by the model the constructed curve are evaluated for the masonry prism with compressive strength $f_{m}^{\prime}=7.90 \mathrm{MPa}$. Fig. (5) compares predictions from the model of the masonry prism with compressive strengths $f_{m}^{\prime}=7.9 \mathrm{MPa}$ to the constructed stressstrain curves by Eq. 7 .

It is clear from Fig. (5) that the results from the DSC/HISS-CT models match well with the observed behavior based on the constructed compressive and tensile behaviors with different peak stresses, different softening region slopes and different residual stresses, Fig. (5).

\section{APPLICATIONS}

Numerical simulations of masonry structures and loaddisplacement responses are considered for masonry prisms with different compressive strengths. Computer programs for two-dimensional analyses [34] with the DSC/HISS model are available. In addition, a computer code that allows the use of the HISS yield surface for both compression and tension in masonry has been developed [42]. The iterativeincremental method with an initial stiffness scheme was applied to analyze unreinforced masonry structures. This method yielded accurate and convergent results for the problems. However, the method can not predict the softening behavior of the displacement - load curve of structure. Hence, the method can be used to determine the linear and hardening behavior of the curve. It is noticeable that parts of unreinforced masonry wall can show the softening behavior [37]. The results of the nonlinear computer analyses are compared with the observed data below.

\subsection{A Masonry Shear Wall}

The mechanical response of the masonry wall illustrated in Fig. (6) was simulated. Experimental tests on a masonry wall were carried out by Raijmakers and Vermeltfoort [43]. With regard to specimens with and without openings two series were tested. Here only windowed panel is considered for the sake of conciseness. The wall was made of wire-cut solid clay bricks with dimensions of $210 \mathrm{~mm}$ x $52 \mathrm{~mm}$ x 100 $\mathrm{mm}$ and $10 \mathrm{~mm}$ thick mortar joints. The height/width ratio was 1 . The dimensions of the wall were $1000 \mathrm{~mm}$ x $990 \mathrm{~mm}$. Two stiff steel beams at the horizontal boundaries of the test setup clamped the top and bottom walls. The geometry of the model and the boundary conditions are shown in Fig. (6). The homogenization model was implemented to analyze the behavior of the masonry wall $[17,18]$. It showed that the responses of the numerical model matched the experimental data. However, the masonry wall was analyzed with the DSC/HISS-CT model using the macro-modeling method.

Bricks and mortar joints are represented by 8-node plane stress continuum elements for the numerical analysis. The wall is modeled by 186 eight-noded isoparametric elements; the mesh has 1230 DOF. The value of the error for the displacement convergence criterion was 5e-4. Fig. (7) shows the mesh that was used for the analysis of the wall and the

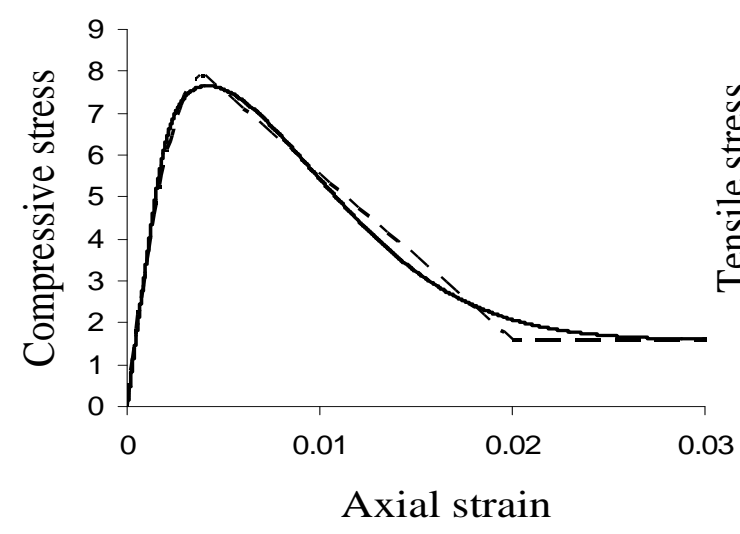

(a)

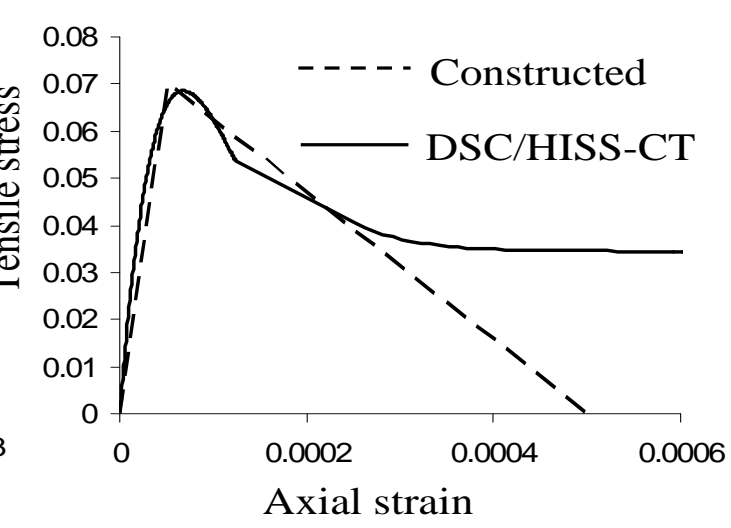

(b)

Fig. (5). Comparison between predictions and data for (a) compressive and (b) tensile behavior of a masonry prism in Pavia test. 


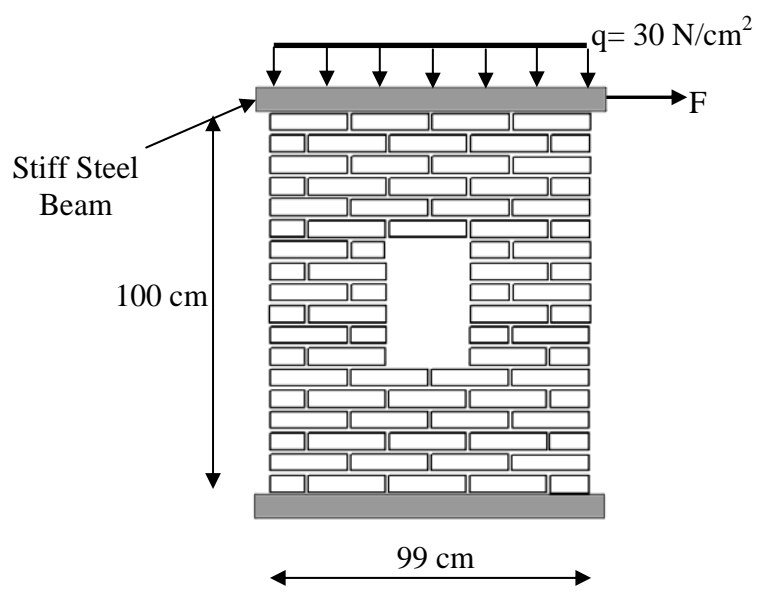

Fig. (6). Geometry of the masonry wall (dimensions in [cm]).

boundary conditions.

Fig. (8) shows a comparison between the load displacement curve predicted by the DSC/HISS-CT model and the test data. The agreement between the predictions and the test data is considered to be good. The analysis of the wall by DSC/HISS-CT did not converge after point A in Fig. (8).

The initial slope of the predicted force-displacement curve from Fig. (8) agrees with the experimental data. It shows that the predicted elasticity modulus is essentially the same as that from the test data. The elasticity modulus for a compressive strength of $10.5 \mathrm{MPa}$ is $7635 \mathrm{MPa}$, Table $\mathbf{1}$, which is 727 times $f_{m}^{\prime}$; the ratio given in FEMA 306 [45] is 550. The International Building Code [46] and MJSC documents [47] recommend $\mathrm{E}$ to be 700 times $f_{m}^{\prime}$, and the Canadian masonry code S304.1 [48] recommends $E$ to be 850 times $f_{m}^{\prime}$. Thus, the predicted ratio using the model proposed in this paper is within the range of reported values.

After point A in Fig. (8), the analysis in the model did not converge. Fig. (8) shows that the predicted ultimate load is about $46.8 \mathrm{kN}$, compared with $47 \mathrm{kN}$ from the test data, or an error of about $0.4 \%$. In addition, the disturbance parameter for point A from Fig. (8) is shown in Fig. (9). A significant part of the wall reached the critical disturbance around 0.90 . This result shows the failure of the wall. The maximum disturbance is 1.00. The predicted failure pattern in Fig. (9) shows that the collapse for both piers was occurred at displacement equal to $14.2 \mathrm{~mm}$, point A in Fig. (8). It is noticeable that the value of the disturbance parameter for both yield surfaces in tension and compression is changed between zero to one. Hence, it is not possible to distinguish among shear, tensile and compressive cracking when the disturbance parameter is plotted. Therefore, the length of the tensile crack for piers may be evaluated as equal to the width of the piers. Hence, in the following, the lateral force is estimated only based on the fracture length and the calibrated parameters that were obtained from the stress level analysis, Table 1. The cohesive strength for tensile behavior, Fig. (3), and the estimate of the lateral load for each pier based on proposed explicit formula [37] are

$$
\begin{aligned}
& C_{t}=3 R_{t} \sqrt{\gamma_{t}}=3 * 1.0 * \sqrt{0.03}=0.52 \\
& T=C_{t} * L_{t} * t=0.52 *(390) * 100=20280 \mathrm{~N} \\
& C=P+T=20280+0.3 * 100 * 390=31980 \mathrm{~N} \\
& F_{1}=\sqrt{\gamma_{t}} * T+\sqrt{\gamma_{c}} * C=\sqrt{0.03} * 20280+\sqrt{0.335} * 31980=22022 \mathrm{~N}
\end{aligned}
$$

Hence, the lateral resistant forced is for both piers as

$$
F=2 F_{1}=2 * 22022=44044 N \approx 44.1 k N
$$

In the above calculation, $t$ is the thickness and $L_{t}$ is named the length of the tensile crack. The estimated lateral load is about $44.1 \mathrm{kN}$, compared with $47 \mathrm{kN}$ from the test

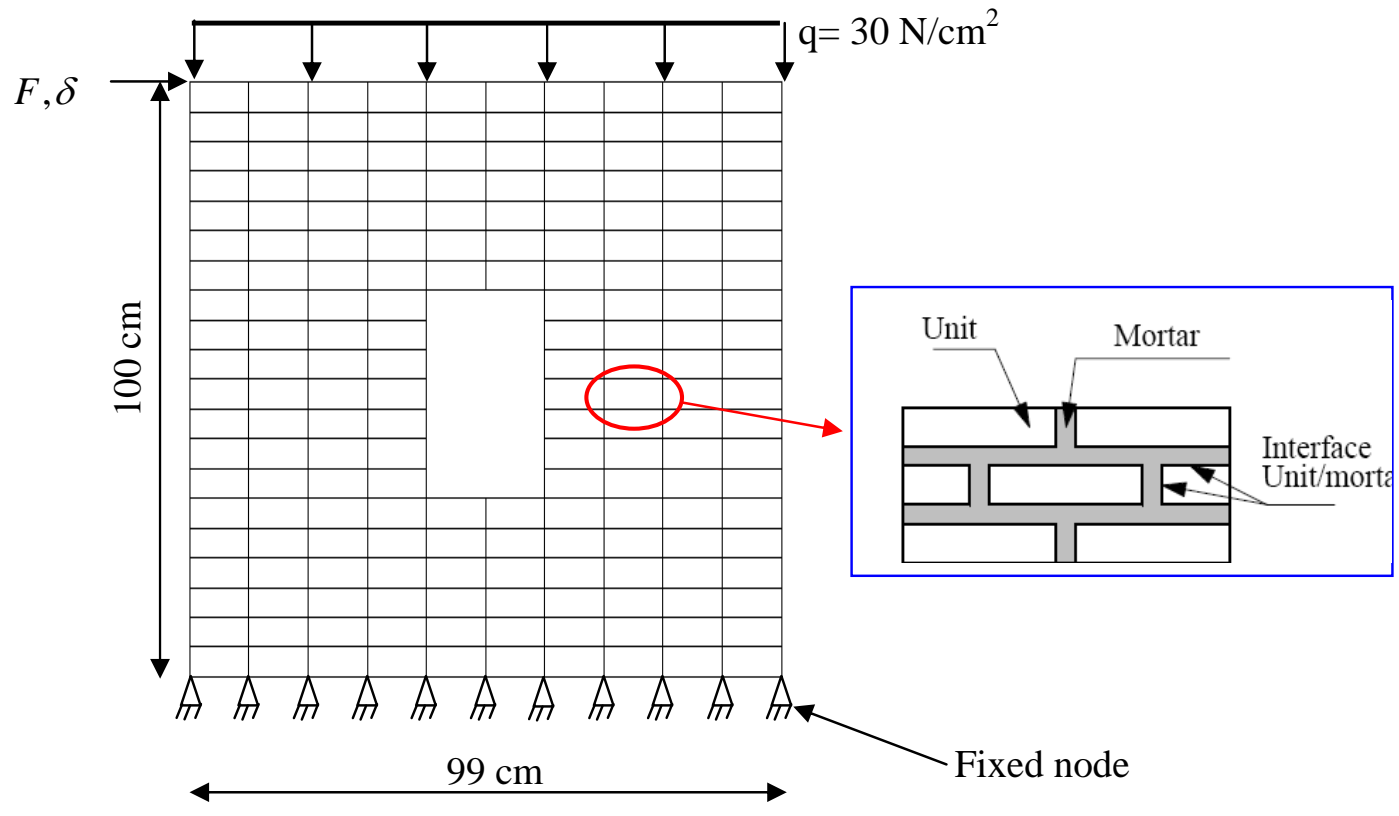

Fig. (7). The boundary conditions and mesh used for the analysis of the masonry wall. 


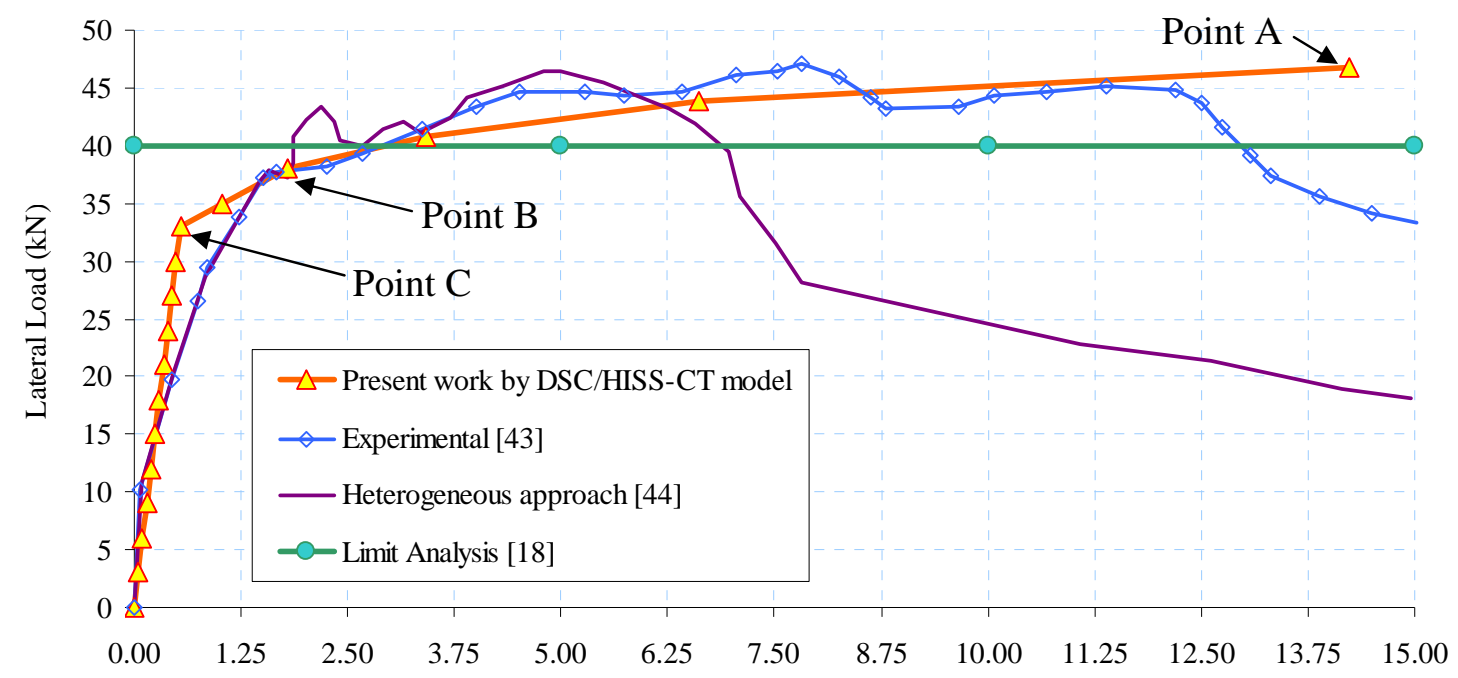

Top Displacement (mm)

Fig. (8). Comparison between the test data and the predicted load-displacement curve for the windowed masonry wall.

Failure region

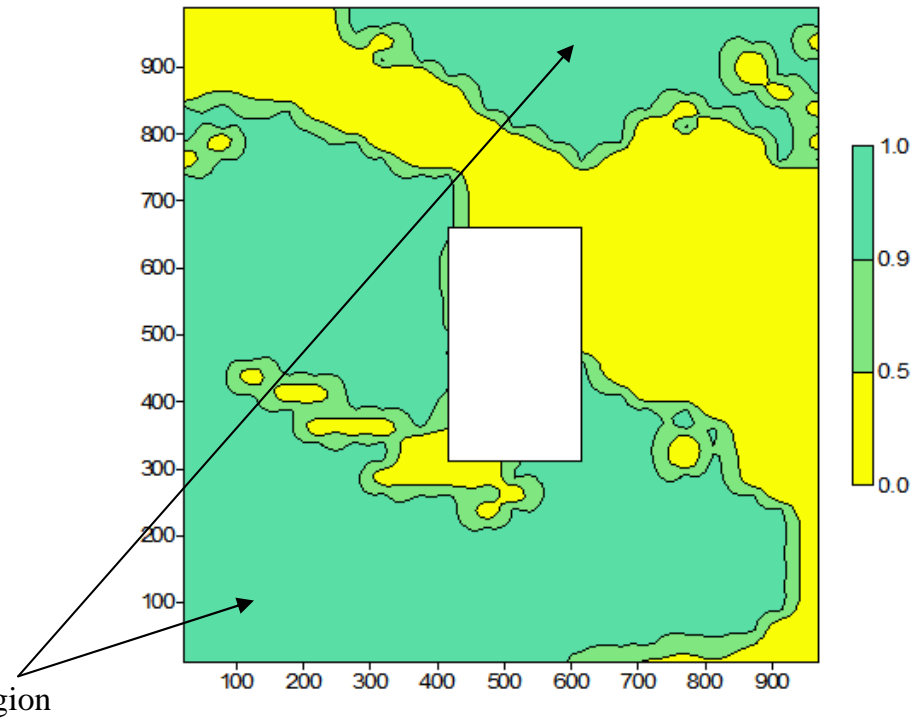

Fig. (9). The variation of disturbance parameter for point A in Fig. (8).

data, or an error of about $6.2 \%$. Therefore, the resistant lateral load may be estimated based on the length of the tensile crack.

The predicted failure pattern in Fig. (9) shows that the wall is collapsed under the lateral load equal to $46.8 \mathrm{kN}$, Point A in Fig. (8). Hence, successive predicted deformed shapes of the wall are evaluated in Fig. (10). The deformed shapes are in accordance with points A, B and C in Fig. (8).

Fig. (10a) shows the deformation of the wall for displacement equal to $0.54 \mathrm{~mm}$, point $\mathrm{C}$ in Fig. (8). It should be noted that the point $\mathrm{C}$ is on linear part of the curve. Hence, the plastic deformation should not be observed when the wall is subjected to the lateral load of the point C. Fig. (10a) shows the small deformation of the wall for the lateral load equal to the point C. However, deformed shapes for points B and A, Fig. (10b) and (c), show the plastic deformation for the wall. Fig. (10c) shows that the bottom of the left pier is collapsed due to combination of the shear stress and the tensile stress. Likewise the right pier of the wall is collapsed due to combination of the shear stress and the compressive stress. The oblique vector on Fig. (10c) shows the direction of the deformation for the right pier. The deformation of the right pier implies the shear failure mode for the pier. It is noticeable that the corners of the window, Fig. (10c), are deformed due to the lateral load.

\subsection{A Two-bay, Two-story Building}

A full-scale, two-story unreinforced masonry building tested at Pavia University was chosen for model validation [49]. This structure has been extensively investigated in the literature [50-52]. The building, with a 6*4.4 m floor plan 


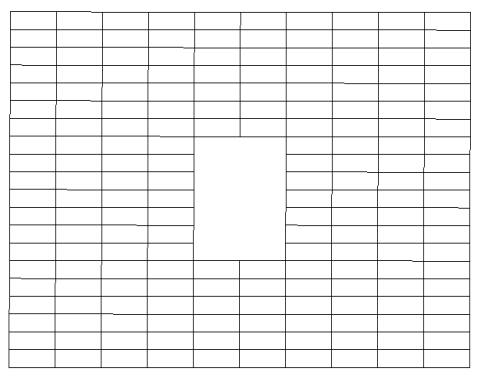

(a) Deformed shape for point $\mathrm{C}$ in Fig. 8 equal to $0.54 \mathrm{~mm}$

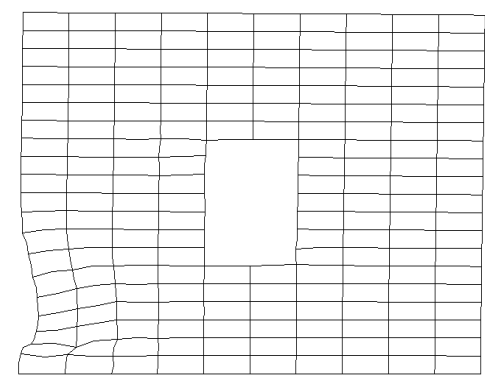

(b) Deformed shape for point $B$ in Fig. 8 equal to $1.80 \mathrm{~mm}$

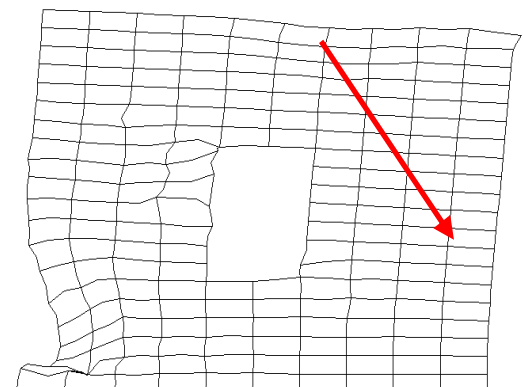

(c) Deformed shape for point A in Fig. 8 equal to $14.2 \mathrm{~mm}$

Fig. (10). Deformed shapes of the wall for different levels of the lateral displacement; the displacements are exaggerated by a factor of 5.

and $6.4 \mathrm{~m}$ in height, contains an almost independent shear wall that is in-plane loaded. The wall considered here (named the "door wall”) is $250 \mathrm{~mm}$ thick and has two doors on the first story and two windows on second story, as shown in Fig. (11). The door wall includes two exterior piers and one interior pier. The exterior pier width and axial loads on the bottom and top levels are equal to $1.15 \mathrm{~m}, 56 \mathrm{kN}$ and $26.9 \mathrm{kN}$, respectively. The interior pier width and axial loads on the bottom and top levels are equal to $1.82 \mathrm{~m}, 133 \mathrm{kN}$ and $64.5 \mathrm{kN}$, respectively.

The properties of the structure used in the model are summarized below [50]:

The maximum compressive strength of a masonry prism, $f_{m}$, is equal to $7.9 \mathrm{MPa}$. The joint tensile strength and the joint cohesion are $0.07 \mathrm{MPa}$ and $0.14 \mathrm{MPa}$, respectively. The joint coefficient of friction is 0.55 . The shear modulus is equal to the effective value, $G_{\text {eff }}=90 f_{m}$. The parameters for
DSC/HISS-CT model were determined in Table 1. Calderini et al. [51] used the finite element method (FEM) to analyze the two-story unreinforced masonry building tested at Pavia University. The model included 2696 nodes and 5128 triangular shell elements. The used mesh in present analysis by DSC/HISS-CT model is shown in Fig. (12). The mesh included 1862 nodes and 496 eight-noded isoparametric elements. Fig. (13) shows comparisons between the present work and experimental data and numerical analyses [51].

The predicted results were compared with results obtained using the equivalent frame model and the Tremuri software [51]. The equivalent frame included 9 nodes, and 3 nodes were fully constrained at the base. The reduce stiffness and full stiffness were used to analyze the building with the equivalent frame. Akhaveissy [52] also analyzed the door wall by the equivalent frame based on proposed close form solution [25].

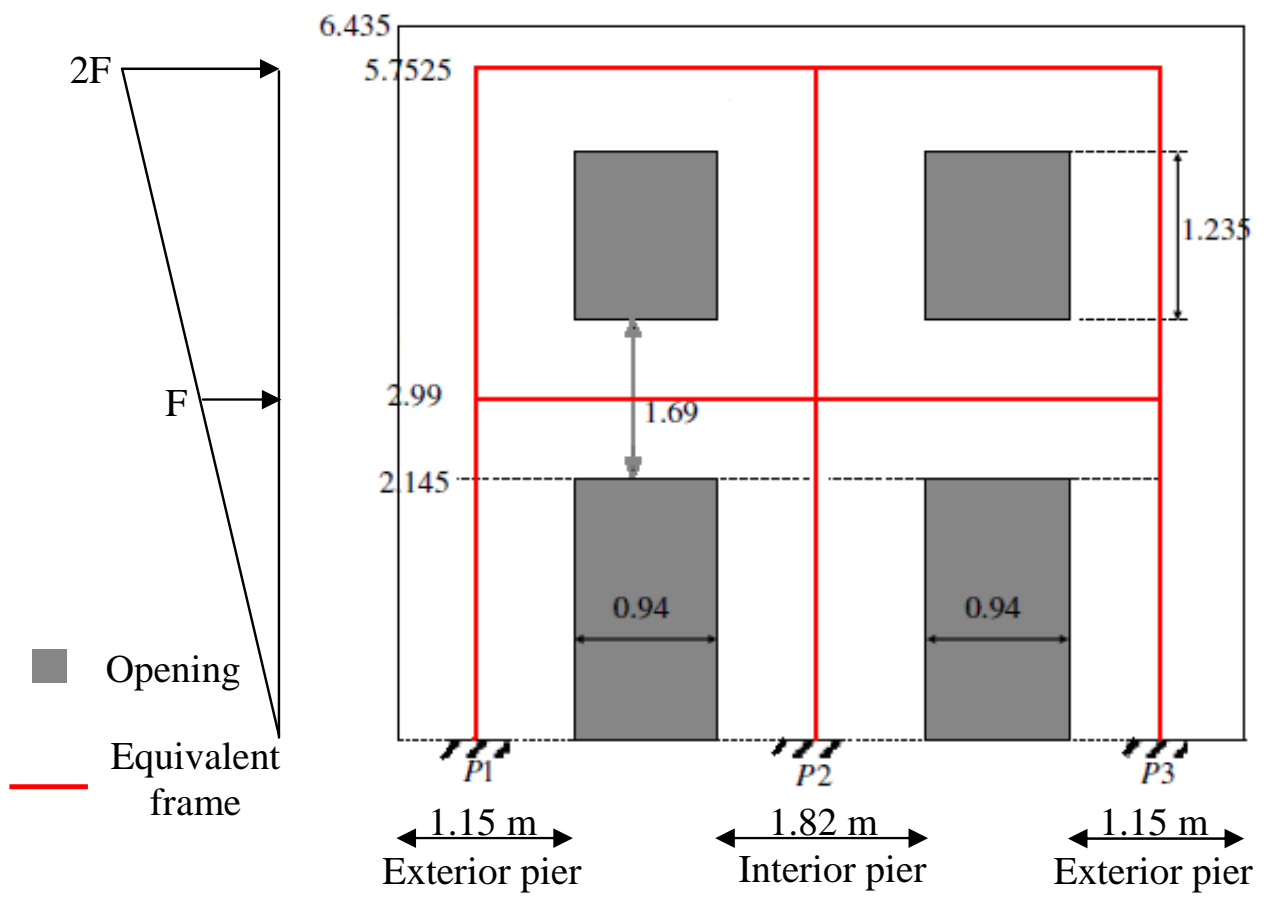

Fig. (11). Door wall of the full-scale, two-story unreinforced masonry building tested at Pavia University. 


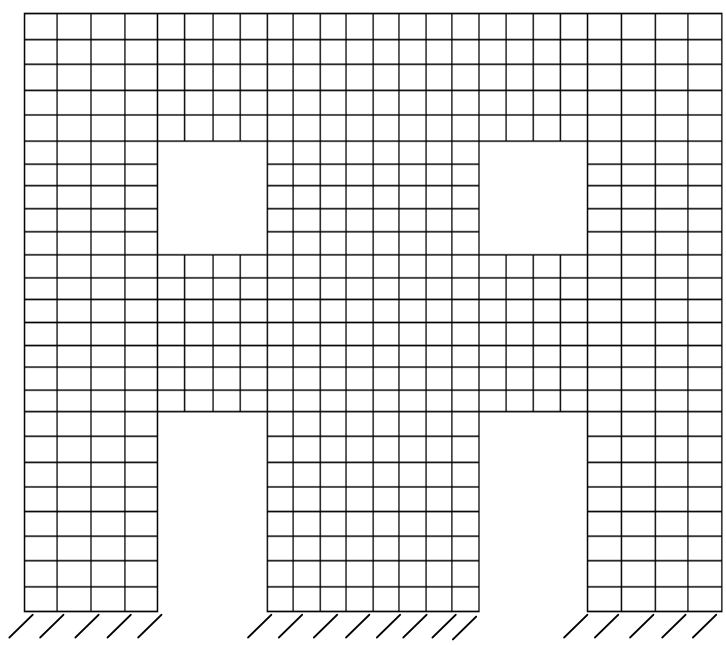

Fig. (12). The mesh used for the analysis of the two-story unreinforced masonry building tested at Pavia University.

Fig. (13) shows that the equivalent frame-reduce stiffness model predicted that the stiffness of the building would be lower than the real stiffness. The value of the ultimate base shear force from the Tremuri software was estimated to be $167 \mathrm{kN}$ whereas the experimental value was determined to be $147 \mathrm{kN}$. The value of ultimate base shear force from the present work and from Belmouden and Lestuzzi [50] was predicted to be $154 \mathrm{kN}$ and $138.4 \mathrm{kN}$, respectively. The finite element method estimate of the force was $157 \mathrm{kN}$. Fig. (13) shows a better agreement between the test data and the present work than with equivalent frame models and finite element method. To consider the damage to the structure, the disturbance parameter for the roof displacement in Fig. (13), point A, is evaluated in Fig. (14). It is noted that a disturbance parameter greater than 0.9 indicates failure. Crack patterns from the experimental test of the URM building at the failure state (a top displacement equal to $24 \mathrm{~mm}$ ) show damage to the piers for the second story as sliding failure and the first story as diagonal crack as well as damage to the deep beam between doors and windows at the first floor [50]. The predicted failure of the piers for the second story and the predicted failure of the deep beams for both stories correlate with the observed data while the damage to the piers for the first story is not seen in the present work. It is noticed that the local failure occurred at the bottom of the piers for the first story. This difference is due to the dissipation of energy by the piers and the deep beams of the second story. Hence, the second story is as the instable floor at the displacement equal to $31.7 \mathrm{~mm}$ and the convergency of the analysis is not occurred for the base shear force larger than $154 \mathrm{kN}$. The deformed shape for point A in Fig. (13) is also plotted in Fig. (15). It should be noticed that form of deformation at the right corner of the roof is due to the concentration of applied lateral external load equal to $2 F$, Fig. (11).

The base shear force is estimated below based only on the explicit formula [37] and calibrated parameters that were obtained from the stress level analysis, Table $\mathbf{1}$. The strength lateral force is calculated for each of the piers, and the base shear force is estimated by minimum the sum of the strength forces of the piers for the first and second story. The strength lateral force is shown in Table 2. To determine the strength of the pier, the fracture length is assumed to be equal to the width of the pier [37]. Therefore, the cohesive strength for tensile behavior, Fig (3), and the estimate of the lateral load for the interior pier $\left(F_{i}\right)$ and the exterior pier $\left(F_{e}\right)$, are as fol-

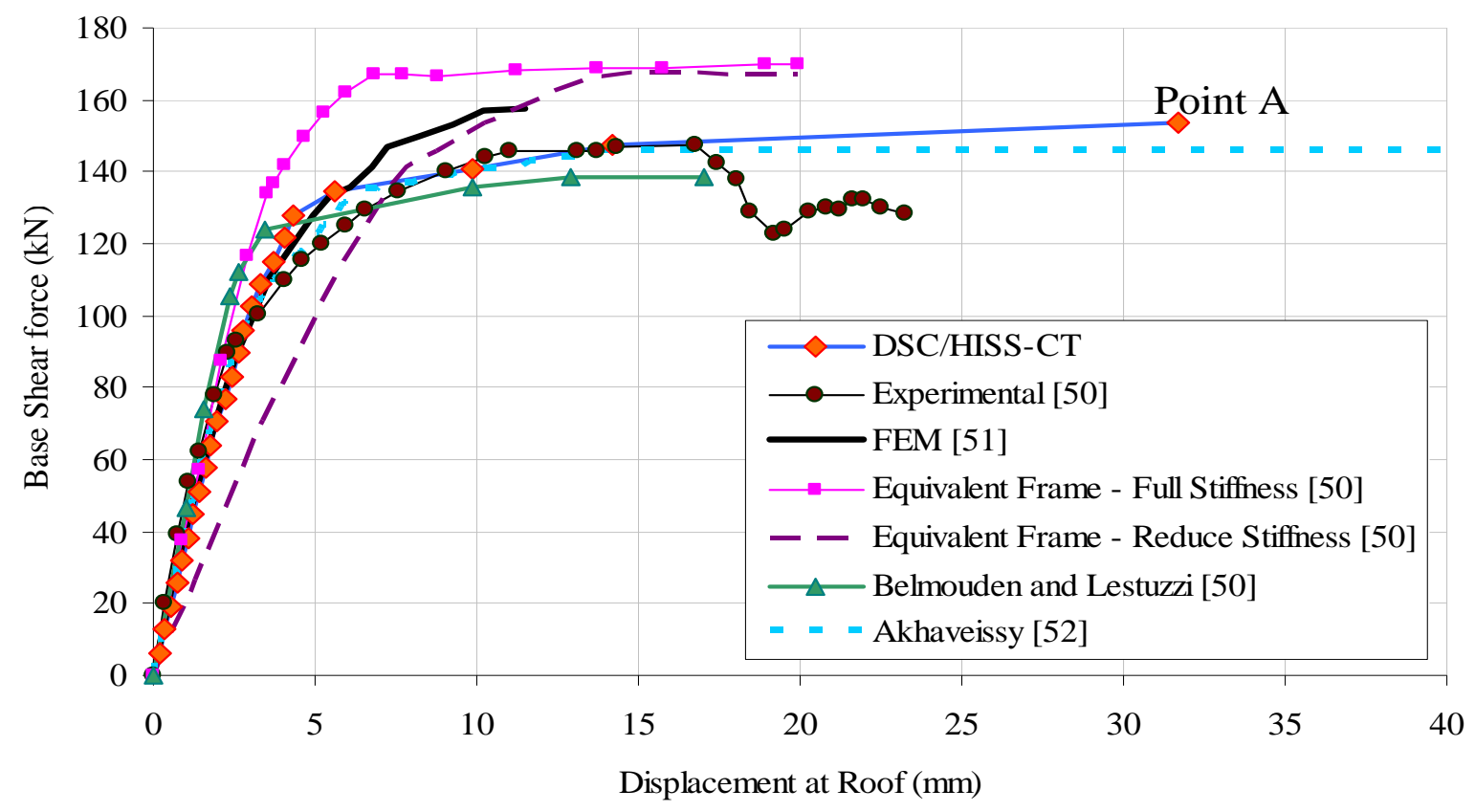

Fig. (13). Comparison of the predicted results with experimental data for the two-story unreinforced masonry building tested at Pavia University. 


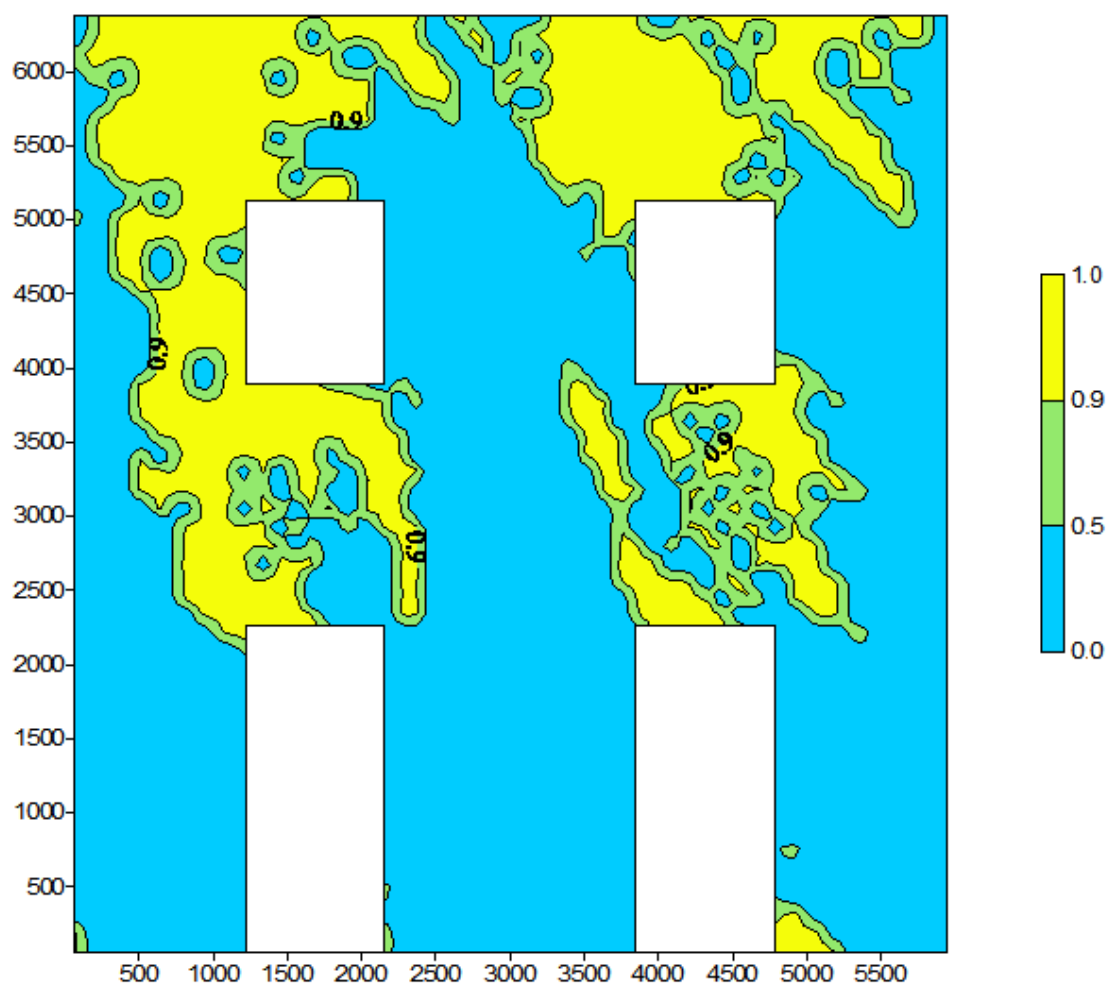

Fig. (14). Damage levels for the URM structure from the present work for displacement at the roof equals $31.7 \mathrm{~mm}$, point A in Fig. (13).

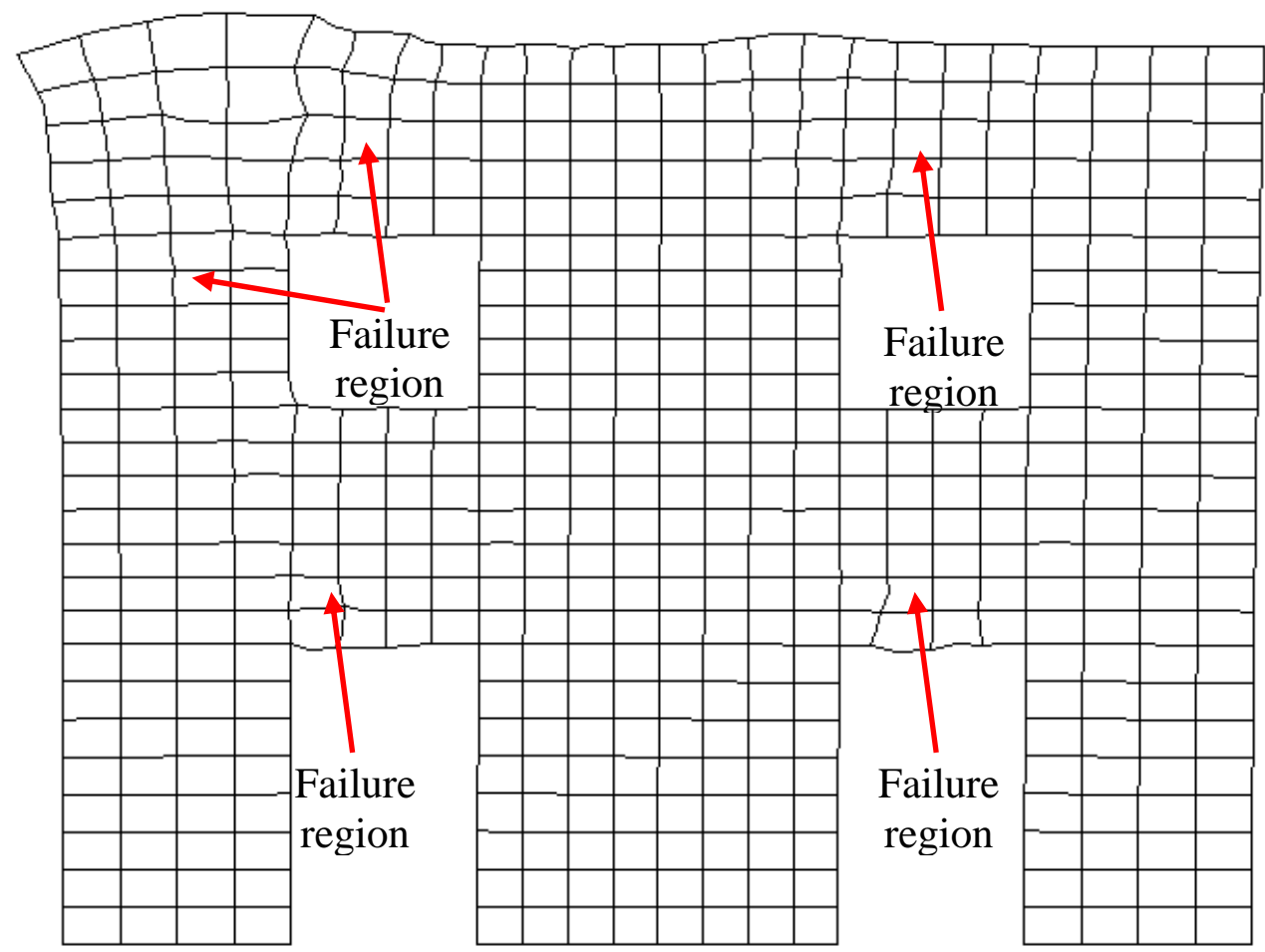

Fig. (15). Deformed shape of the wall for the base shear force of the point A in Fig. 13; the displacements are exaggerated by a factor of 2

lows. Subscript $\mathrm{i}$ is shown for the interior pier and e for the exterior pier.

$$
C_{t}=3 R_{t} \sqrt{\gamma_{t}}=3 * 0.2 * \sqrt{0.03}=0.10392
$$


Table 2. The Ultimate Shear Force, $F$, for the Pavia Test

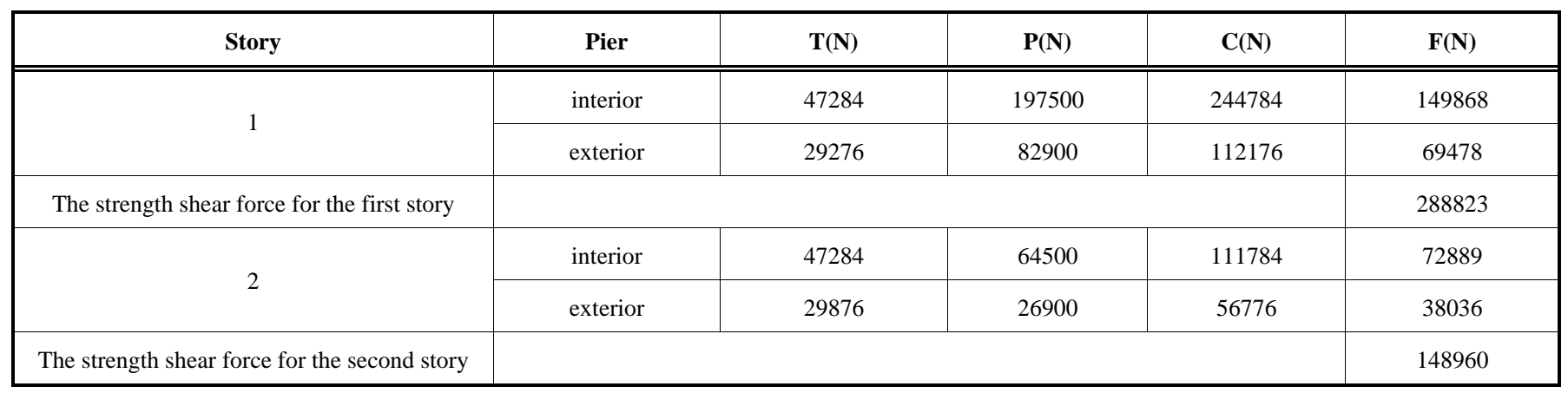

It is noticeable that the strength shear force for the stories are calculated based on the sum of the strength forces for both exterior piers and interior pier, Table 2 . Hence, comparison between the strength shear force for the first story and the second story show that the second story is collapsed sooner than the first story. Consequently, the ultimate shear force is equal to the strength shear force of the second story. The estimated lateral load based on the close form solution is about $148.96 \mathrm{kN}$, compared with $147 \mathrm{kN}$ from the test data, an error of about $1.3 \%$. Therefore, the resistant lateral load may be estimated based on the explicit formulation presented here.

The pushover curve in Fig. (13) provides also important information on the ultimate drift of the walls, which is useful to determine the pseudo ductility. In particular, the ultimate drift, $\delta_{u}$, is evaluated as the drift in relation of a shear strength degradation. The yield $\operatorname{drift}, \delta_{y}$, is determined equating the areas under the equivalent bilinear 1DOF model and the actual capacity curve, as suggested by many codes of practice [53]. In the present case values of the ultimate and yield drifts are equal to $31.7 \mathrm{~mm}$ and $3.64 \mathrm{~mm}$, respectively. The pseudo ductility $\mu$ is hence determined as the ratio between ultimate and yield drift as:

$\mu=\frac{\delta_{u}}{\delta_{y}}$

From simulations results, the pseudo ductility for the building is 8.7. The deflection amplification factor, $R_{\mu}$, can be determined through Newmark and Hall method [54] and is equal to 4.05. The over strength factor is also computed. It is equal to 1.85 . The strength reduction factor due to the nonlinear hysteretic behavior is defined as the ratio between the elastic and inelastic strength demand, it is equal to 0.29.

Finally, the seismic modification factor is determined as the product between the deflection amplification factor, the over strength factor, and the strength reduction factor. Consequently, in the present case, the seismic modification factor is equal to 2.17 which is comparable with experimental data.

\section{CONCLUSIONS}

A nonlinear finite element method with eight-noded isoparametric quadrilateral elements for combined masonry blocks and mortar joints was used to predict the behavior of unreinforced masonry structures. The disturbed state concept (DSC) and the modified hierarchical single surface (HISSCT) plasticity model with associated flow rules were used to characterize the compressive and tensile yields of the masonry structures. The model can account for micro-cracking in the masonry which leads to softening and fracture. The HISS-CT plasticity model involves two separate yield surfaces for compressive and tensile yield; the continuous nature of the proposed yield surface prevent computational difficulties in currently available discontinuous or multiple surfaces models, such as critical state and cap models [31]. The DSC model allows for the generation of discontinuities in the material microstructure during loading (unloading), and it does not require external enrichments to allow coupling between continuous and discontinuous parts within the deforming material [55]. Moreover, the same framework in the DSC can be used to model the behavior of interfaces and joints [31].

The DSC/HISS-CT model for masonry was validated at the specimen level. It was also applied successfully for a number of unreinforced masonry prism specimens. The computational predictions correlated well with test data and the constructed model. The model was also implemented in a finite element procedure to analyze the boundary problems. The model predictions for the masonry shear wall and the unreinforced masonry building with two stories correlated well with the test data. The model can predict the hardening and softening behavior of materials. In addition, a closed form solution was proposed based on the calibrated parameters of the DSC/HISS-CT model. The closed form solution predicts the ultimate lateral load of an unreinforced masonry wall relatively well. Therefore, the DSC/HISS-CT model can be used satisfactorily to analyze masonry structures similar to those considered herein.

\section{DISCLOSURE}

Part of information included in this article has been previously published in "ARCHIVES OF COMPUTATIONAL 
METHODS IN ENGINEERING Volume 18, Number 4 (2011), 485-502, DOI: 10.1007/s11831-011-9067-4”.

\section{CONFLICT OF INTEREST}

The authors confirm that this article content has no conflicts of interest.

\section{ACKNOWLEDGEMENTS}

None decleared.

\section{REFERENCES}

[1] H.B. Kaushik, D.C. Rai, and S.K. Jain, "Uniaxial compressive stress-strain model for clay brick masonry" Curr. Sci., vol. 92, no. 4, pp. 497-501, 2007.

[2] H.B. Kaushik, D.C. Rai, and S.K. Jain, "Stress-Strain Characteristics of Clay Brick Masonry under Uniaxial Compression,” J. Mater. Civil Eng. ASCE, vol. 19, no. 9, pp. 728739, 2007.

[3] A. Tena-Colunga, A. Juarez-Angeles, and V.H. Salinas-Vallejo, "Cyclic behavior of combined and confined masonry walls," Eng. Struct., vol. 31, pp. 240-259, 2009.

[4] K. Chaimoon, and M.M. Attard, "Experimenatl and numerical investigation of masonry under three-point bending (in-plane)," Eng. Struct., vol. 31, pp. 103-112, 2009.

[5] G. Vasconcelos, and P.B. Lourenco, "Experimental characterization of stone masonry in shear and compression," Constr. Build. Mater., vol. 23, pp. 3337-3345, 2009.

[6] L. Pasticier, C. Amadio, and M. Fragiacomo, "Non-linear seismic analysis and vulnerability evaluation of a masonry building by means of the SAP2000 V.10 code," Earthquake Eng. Struct. Dyn., vol. 37, pp. 467-485, 2008.

[7] A. Gabor, E. Ferrier, and H.P. Jacquelin, "Analysis and modeling of the in-plane shear behavior of hollow brick masonry panels," Constr. Build. Mat., vol. 20, pp. 308-321,2006.

[8] A. Brencich, L. Gambarotta, and S. Lagomarsino, A macroelement approach to the three-domensional seismic analysis of masonry buildings. 11th European Conference on Earthquake Engineering, Balkema, Rotterdam, 1998.

[9] J. Park, P. Towashiraporn, J.I. Craig, and B.J. Goodno, "Seismic fragility analysis of low-rise unreinforced masonry structures,” vol. 31, pp. 125-137, 2009.

[10] M. Rota, A. Penna, and G. Magenes, “A methodology for deriving analytical fragility curves for masonry buildings based on stochastic nonlinear analyses,” Eng. Struct., vol. 32, pp. 1312-1323, 2010.

[11] M. Bruneau, "State-of-the-art report on seismic performance of unreinforced masonry buildings,” J. Struct. Eng., vol. 120, no. 1, pp. 230-251, 1994.

[12] C. Alessandri, and C.A. Brebbia, "Strength of masonry walls under static horizontal loads: boundary element analysis and experimental tests," Eng. Anal., vol. 4, no. 3, pp. 118-134, 1987.

[13] G. Milani, P. Lourenco, and A. Tralli, "3D homogenized limit analysis of masonry buildings under horizontal loads,” Eng. Struct., vol. 29, pp. 3134-3148, 2007.

[14] G. Milani, P. Lourenco, and A. Tralli, "Homogenised limit analysis of masonry walls, Part I: Failure surfaces,” Comp. Struct., vol. 84, pp. 166-180, 2006

[15] A. Cecchi, and G. Milani, "A kinematic FE limit analysis model fot thick English bond masonry walls,” Int. J. Solids Struct., vol. 45, pp. 1302-1331, 2008.

[16] G. Milani, E. Miani, and A. Tralli, "Approximate limit analysis of full scale FRP-reinforced masonry buildings through a 3D homogenized FE package,” Compos. Struct., vol. 92, pp. 918-935, 2010.

[17] G. Milani, "Simple lower bound limit analysis homogenization model for in-and out-of-plane loaded masonry walls," Constr. Build. Mater., vol. 25, pp. 4426-4443, 2011.

[18] G. Milani, "Simple homogenization model for the non-linear analysis of in-plane loaded masonry walls.," Comput. Struct., vol. 89, pp. 1586-1601, 2011.
[19] P. Roca, "Assessment of masonry shear-walls by simple equilibrium models,” Constr. Build. Mater., vol. 20, pp. 229-238, 2006.

[20] M. Shariq, H. Abbas, H. Irtaza, and M. Qamaruddin, "Influence of openings on seismic performance of masonry building walls," Build. Environ., vol. 43, pp. 1232-1240, 2008.

[21] G. Milani, K. Beyer, and A. Dazio, "Upper bound limit analysis of meso-mechanical spandrel models for the pushover analysis of 2D masonry frames,” Eng. Struct., vol. 31, pp. 2696-2710, 2009.

[22] J. Lopez, S. Oller, E. Onate, and J. Lubliner, "A homogeneous constitutive model for masonry," Int. J. Numer. Meth. Eng., Vol. 46, pp. 1651-1671, 1999.

[23] I. Sharif, C.S. Meisl, and K.J. Elwood, "Assessment of ASCE 41 Height-to-thickness ratio limits for URM walls," Earthquake Spectr, vol.23, no. 4, pp. 893-908, 2007.

[24] C.S. Meisl K.J. Elwood, and C.E. Ventura, "Shake table tests on the out-of-plane response of unreinforced masonry walls," Can. J. Civ. Eng., vol. 34, pp. 1381-1392, 2007.

[25] A.H. Akhaveissy, "Lateral Strength Force of URM Structures based on a Constitutive Model for Interface Element,” Lat. Am. J. Solids Struct., vo. 8, pp. 445-461, 2011.

[26] Applied Technology Council (ATC), "Evaluation of earthquake damaged concrete and masonry wall buildings", Technical Resources Publication no. 307, Federal Emergency Management Agency (FEMA-307), Washington (DC), 1999.

[27] C.S. Desai, S. Somasundaram , and G. Frantziskonis, "A hierarchical approach for constitutive modeling of geologic materials," Int. J. Numer. Anal. Methods Geomech., vol. 10, pp. 225-257, 1986.

[28] C.S. Desai, and M.R. Salami, "A constitutive model for rocks," $J$. Geotech. Eng., ASCE, vol. 113, pp. 407-423, 1987.

[29] C.S. Desai, and J. Toth, 'Disturbed state constitutive modelling based on stress-strain and nondestructive behavior," Int. J. Solids Struct., vol. 33, pp. 1619-1650, 1996.

[30] M.R. Salami, and C.S. Desai, "Constitutive modeling including multiaxial testing for plain concrete under low confining pressure," J. Mater. Am. Concrete Inst., vol. 87, no. 3, pp. 228-236, 1990.

[31] C.S. Desai, "Mechanics of materials and interfaces," the disturbed state concept, CRC Press: Boca Raton, Florida, U.S.A, 2001.

[32] C.S. Desai, "Mechanistic pavement analysis and design using unified material and computer models,"Keynote Paper, Proc. 3rd Intl. Symposium on 3D Finite Elements for Pavement Analysis, Design and Research, Amsterdam. Netherlands, 2002.

[33] C.S. Desai, "Unified DSC constitutive model for pavement materials with numerical implementation," Int. J. Geomech. ASCE, vol. 7, no. 2, pp. 83-101, 2007.

[34] C. Shao, and C.S. Desai, "Implementation of DSC model and application for analysis of filed pile tests under cyclic loading," Int. J. Num. Anal. Method Geoemch., vol. 24, no. 6, pp. 601-624, 2000.

[35] S.K. Pradhan, and C.S. Desai, "DSC model for soil and interface including liquefaction and prediction of centrifuge test," $J$. Geotech. Geoenviron. Eng. ASCE, vol. 132, no. 2, pp. 214-222, 2006.

[36] O.C. Zienkiewicz, S. Valliapan, and I.P. King, "Stress analysis of rock as a no tension material," Geotechnique, vol. 18, no. 1, 1968.

[37] A.H. Akhaveissy, and C.S. Desai, "Unreinforced Masonry Walls: Nonlinear Finite Element Analysis with a Unified Constitutive Model," Arch. Computat. Methods Eng., vol.18, no. 4, 485-502, 2011.

[38] A.H. Akhaveissy, and C.S. Desai, "Application of DSC Model for Nonlinear Analysis of Reinforced Concrete Frames,” Finite Ele. Anal. Design J., vol. 50, pp. 98-107, 2012.

[39] B.H. Pandey, and K. Meguro, "Simulation of Brick masonry wal behavior under in plane lateral loading using applied element method," 13th World Conference on Earthquake Engineering, Vancouver, B.C., Canada, August 1-6, 2004, paper No. 1664.

[40] W.A. Weibull, "A statistical distribution function of wide applicability,” App. Mech., vol. 18, pp. 293-297, 1951.

[41] C. Yalcin, and M. Saatcioglu, "Inelastic analysis of reinforced concrete columns,” Comp. Struct., vol. 77, pp. 539-555, 2000.

[42] A.H. Akhaveissy, and C.S. Desai, S.A. Sadrnejad, and H. Shakib, "Implementation and Comparison of Generalized Plasticity and Disturbed State Concept for Load-Deformation Behavior of Foundation,” Scientia Iranica J., Trans. A: Civ Eng., vol. 16, no. 3, pp. 189-198, 2009. 
[43] T.M.J. Raijmakers, and A. Vermeltfoort, "Deformation controlled tests in masonry shear wall (in Dutch)” Report B-92-1156, TNOBouw, Delft, The Netherlands., 1992.

[44] P.B. Lourenco, R. de Borst, and J.G. Rots, "A plane stress softening plasticity model for orthotropic materials," Int. J. Numer. Methods Eng., vol. 40, pp. 4033-57, 1997.

[45] Federal Emergency Management Agency (FEMA), "Evaluation of earthquake damage concrete and masonry wall buildings", basic procedure manual, ATC-43, FEMA306, Applied Technology Council, Calif., 1999.

[46] International Code Council, International building code, 2003.

[47] Masonry Standard Joint Committee (MSJC), "Building code requirements for masonry structures”, ACI 530-02/ASCE 502/TMS 402-2, American Concrete Institute, Structural Engineering Institute of the American Society of Civil Engineers., The Masonry Society, Detroit., 2002.

[48] Canadian Standard Association (CSA), "Design of masonry structures”, S304.1, Ontario, Canada., 2004.

[49] G. Magenes, and G.M. Calvi, "In-plane seismic Response of Brick Masonry Walls,” Earthquake Eng. Struct. Dyn., vol.26, pp. 10911112, 1997.
[50] Y. Belmouden, and P. Lestuzzi, "An equivalent frame model for seismic analysis of masonry and reinforced concrete buildings," Construct. Build. Mater. vol. 23, pp. 40-53, 2009.

[51] C. Calderini, S. Cattari, and S. Lagomarsino, "In plane seismic response of unreinforced masonry walls: comparison between detailed and equivalent frame models," COMPDYN 2009, ECCOMAS Thematic Conference on Computational Methods in Structural Dynamics and Earthquake Engineering In: Papadrakakis M, Lagaros ND, Fragiadakis M (Eds.) Rhodes, Grecce, 22-24 June, 2009.

[52] A.H. Akhaveissy, "Finite Element Nonlinear Analysis of High-Rise Unreinforced Masonry Building,” Lat. Am. J. Solids Struct., vol. 9, pp. 547-567, 2012.

[53] ATC40, "Seismic evaluation and retrofit of concrete buildings", Vol. 1, Applied Technology Council (ATC), 1996.

[54] N.M. Newmark, and W.J. Hall, "Seismic design criteria for nuclear reactor facilities”, Report No. 46, Building Practices for Disaster Mitigation, National Bureau of Standards, U.S. Department of Commerce, 209-236, 1973.

[55] H.B. Muhlhaus, "Continuum Models for Materials with Microstructure,” John Wiley \& Sons: Chichester, U.K. 1995.

Received: February 08, 2012

Revised: July 10, 2012

Accepted: July 11, 2012

(C) A.H. Akhaveissy; Licensee Bentham Open.

This is an open access article licensed under the terms of the Creative Commons Attribution Non-Commercial License (http://creativecommons.org/licenses/ by-nc/3.0/) which permits unrestricted, non-commercial use, distribution and reproduction in any medium, provided the work is properly cited. 